\title{
Preface to Special Issue "International Year of the Periodic Table: From Mendeleev to Cluster Chemistry"
}

\author{
Richard D. Adams ${ }^{1} \cdot$ Boon Teo $^{2} \cdot$ Vladimir P. Fedin ${ }^{3}$
}

Published online: 3 September 2019

(C) Springer Science+Business Media, LLC, part of Springer Nature 2019

The discovery of "periodicity" in the chemical properties of the elements was a breakthrough of enormous proportions. It allowed chemists to seek new properties among the known elements and seek elements that had at the time not yet been discovered. The leader in this discovery was Dmitri Mendeleev who reported is findings in 1869 , 150 years ago this year [1]. From this report emerged the relationship known today as the Periodic Table of the Elements [2].

To honor this seminal discovery, the United Nations has proclaimed the year 2019 as the "International Year of the Periodic Table of Chemical Elements". https://iupac.org/ united-nations-proclaims-international-year-periodic-tablechemical-elements/.

To celebrate this momentous occasion, we have organize this special issue of the Journal of Cluster Science on the theme, "International Year of the Periodic Table: From Mendeleev to Cluster Chemistry". It has been our goal to show the scope, depth and variety in the chemistry of the elements across the Periodic Table as it is unfolding in the emerging field of Cluster Science.

Richard D. Adams

adamsrd@mailbox.sc.edu

Boon Teo

boonkteo@xmu.edu.cn

Vladimir P. Fedin

cluster@niic.nsc.ru

1 Dept. of Chemistry and Biochemistry, University of South Carolina, Columbia, SC 29208, USA

2 College of Chemistry and Chemical Engineering, Xiamen University, Xiamen 361005, Fujian, China

3 Nikolaev Institute of Inorganic Chemistry, Novosibirsk, Russia

In this special issue, you will find reports on investigations of the structure and bonding polyhedral borate clusters; the first example of a tricapped tetrahedral cluster of silver atoms containing with an interstitial hydrido ligand; new copper-indium-chalcogenide cluster complexes and new cubane-structured nickel cluster complexes with unusual magnetic properties. We thank the contributors for their valuable contributions and hope the readers will receive inspirations to pursue new directions in this exciting field of research.

\section{References}

1. D. Mendelejeff (1869). Zeitschrift fur Chemie 5, 405-406.

2. E. R. Scerri (2019). Chem. Eur. J. 25, 7410-7415.

Publisher's Note Springer Nature remains neutral with regard to jurisdictional claims in published maps and institutional affiliations. 